\title{
Coping strategies and social environment of patients with sudden hearing loss
}

\section{BACKGROUND}

Hearing impairment has a significant physiological, psychological, and social impact on one's life. The primary aim of this study was to explore which coping strategies are most frequently used by patients with a sudden hearing impairment within the period of just a few days after the first symptoms appear.

PARTICIPANTS AND PROCEDURE

Sixty-four patients were asked to complete the coping inventory COPE between the first and the fifth day following the diagnosis of hearing loss.

\section{RESULTS}

The start of hearing impairment acts as a trigger for the use of a problem-solving coping strategy. Social support from the family represents an important source of help for patients with sudden hearing loss. Humour as a coping strategy was found to be used as a means of easing the current unfavourable situation and concealing one's emotions from others.

\section{CONCLUSIONS}

Active coping and seeking social support were the most frequently used coping strategies.

KEY WORDS

social support; stress; hearing impairment

ORGANISATION - Pavol Jozef Šafárik University in Košice, Slovak Republic

AUthors' Contributions - A: Study design - B: Data collection - C: Statistical analysis - D: Data interpretation .

E: Manuscript preparation · F: Literature search · G: Funds collection

Corresponding Author - Monika Hricová, Ph.D., Department of Psychology, Faculty of Arts, Pavol Jozef Šafárik

University in Košice, 9 Moyzesova Str., 04059 Košice, Slovak Republic, e-mail: monika.hricova@upjs.sk

TO CITE THIS ARTICLE - Hricová, M. (2018). Coping strategies and social environment of patients with sudden hearing

loss. Health Psychology Report, 6(3), 216-221. doi: https://doi.org/10.5114/hpr.2018.75122

RECEIVED 01.02.2018 · REVIEWED $\cdot 01.03 .2018 \cdot$ ACCEPTED 10.03.2018 $\cdot$ PUBLISHED 20.04.2018 


\section{BACKGROUND}

Hearing makes it possible to analyse various auditory impulses such as the intensity, frequency, colour, source, and the direction of sound. However, its most important role lies in communication. Therefore, hearing impairment has a significant physiological as well as psychological and social impact on one's life. Moreover, a sudden loss of hearing can be especially stressful (Luey, Glass, \& Elliot, 1995).

Sudden hearing loss is reflected by the acute dysfunction of the inner ear within 72 hours (Wilson, Byl, \& Laird, 1980). Its main symptom is sudden and is usually demonstrated by a unilateral hearing loss for sound with a magnitude greater than $30 \mathrm{~dB}(\mathrm{Oh}$ et al., 2007). Given that it usually occurs when one is in good health, its abruptness may cause a psychological shock that is hard to cope with. For most people, sudden hearing loss is a shock, source of unpleasant emotions and frustration of needs (Garnefski \& Kraaij, 2012). This represents a psychologically difficult situation and subsequently a deteriorating quality of life and emotional well-being (Hasson et al., 2010).

Sudden hearing loss is also accompanied by various psychosocial disadvantages, especially in the social environment, in relationships with friends and family members (Garnefski \& Kraaij, 2012). Social support plays an important role in health protection in adaptation to chronic illness (Dimond, 2007) and is a strong predictor of overall quality of life of people with hearing impairment (Lovretić et al., 2016). Chen and Most (2009) found that people with hearing loss have a reduction in normal social activities and increased problems in their relationship with family or friends. The failure to communicate may be met with misunderstanding and embarrassment (Hasson et al., 2010). Individuals with acquired hearing impairment have been found to often feel depressed and experience higher dissatisfaction with their lives as well as greater social isolation, when compared with a healthy population (Garnefski \& Kraaij, 2012; Hallam et al., 2006). A person with an impaired hearing condition may often struggle to follow conversations and may find it too awkward to keep asking for repetition. On the other hand, family members may get annoyed by constantly repeating what has just been said (Feher-Prout, 1996). Thus, a patient with a hearing impairment is often forced to make a huge effort just to focus on regular communication because the sounds are perceived as distorted. As a result, his or her speech may seem too loud for the social environment due to the absence of feedback, which may cause negative reactions from others who are part of the conversation, and may even lead to stigmatisation. Although using a hearing aid might allevi- ate these problems, it cannot fully compensate for persisting and deteriorating hearing impairment, especially when communicating in a very loud environment or a when in conversation with several people at the same time (Feher-Prout, 1996).

Despite the fact that sudden hearing loss is accompanied by several psychosocial consequences, coping with sudden hearing loss has rarely been explored. In most studies that have been reported in the literature, coping with an acquired hearing impairment was measured many months or years after the disease onset. From the existing research it has been found that seeking social support is often used as the main coping strategy by these patients (Hallberg, 1999). However, it was also found that it is only used in the closest circle of friends and family, and the patients seem to be isolated from broader social contacts. Hallberg and Carlsson (1991) have found that two common coping strategies have been used by participants with acquired hearing loss. These are the strategy "to control the social scene" and the strategy "to avoid the social scene”. Murray, Spry, and Mouze (2009) suggested that patients with impaired hearing may try to deal with the communication barrier by avoiding conversations and interaction with others. Hallberg (1999) states that a patient with impaired hearing often uses both problem-solving and avoidance coping strategies. For example, a problem-solving strategy could be reflected by sitting close to the speaker or lip-reading actively, while an avoidance coping strategy would be represented by the preference of silence, solitude, or escape from any communication situation (e.g. eating out, visiting friends) (Hallberg, 1999). In relation to this, Andersson and Hägnebo (2003) found that coping is mostly represented in the forms of problem solving, self-controlling, seeking social support, and distancing. The problem-solving coping strategy could be explained also with the initial crisis phase of rapid loss of hearing. The crisis phase is the initial period of readjustment and coping after the problem has been clarified through a diagnosis and initial treatment plan (Rolland, 1987). During this period, the hearing-impaired patient should learn how to deal with illness-related symptoms and seek medical help. Prompt medical treatment and prompt diagnosis ensure that there are the best chances of recovery (Luey, Glass, \& Elliot, 1995).

The aim of this study was to explore the use of coping strategies by patients suffering from sudden hearing impairment. The study focused on the period of the few days after the first symptoms appear. At that point, the hearing loss stress is the greatest. An additional aim was to gain a deeper insight into the social aspects of coping with the situation, especially in the context of family and friends.
Sudden hearing loss and coping strategies 


\section{PARTICIPANTS AND PROCEDURE}

\section{PARTICIPANTS}

Sixty-four hospitalised patients participated in the study. The respondents had been diagnosed with sudden unilateral hearing loss. In total, 32 men (50.00\%) and 32 women $(50.00 \%)$ participated in the study. The mean age of women was $M=48.82$ years $(S D=$ 13.74, range 23-68 years), while the mean age of men was $M=44.75$ years ( $S D=14.33$, range $20-62$ years). The mean length of time between the reported onset of symptoms and the diagnosis of hearing loss was $M=2.8$ days $(S D=1.63$, range $1-5$ days $)$. Informed consent was obtained from all individual participants included in the study.

\section{MEASURES}

The coping inventory COPE (Carver, Scheier, $\&$ Weintraub, 1989) was used to measure coping. The respondents were asked to think of a stressful situation that is associated with the hearing impairment and answer three questions: " 1 . What do you usually do when you are stressed due to your impairment in general?", "2. What do you usually do when you are stressed due to your impairment in the presence of your family members?" and "3. What do you usually do when you are stressed due to your impairment in the presence of your friends?". The respondents had to rate each coping item on a five-point scale ranging from 1 (I usually don't do this at all) to 5 (I usually do this a lot), separately for every question.

Five scales (active coping, planning, suppression of competing activities, restraint coping, and instrumental social support) measure the problem-focused coping style, another six (humour, positive reinterpretation and growth, denial, emotional social support, acceptance, turning to religion) refer to emotion-focused coping, and the last four scales (focus on and venting emotions, behavioural disengagement, mental disengagement, and substance use) reflect the maladaptive coping style [12].

\section{RESULTS}

The mean scores on the preferred coping strategies in general are presented in Table 1 . As can be seen in Table 1 , active coping $M=4.28(S D=1.45)$, turning to religion $M=3.64(S D=1.64)$, and emotional social support $M=3.60(S D=1.70)$ were the the most frequently used coping strategies with stress caused by sudden hearing impairment. On the other hand, substance use $M=1.89(S D=1.37)$, acceptance $M=2.05(S D=1.36)$, and behavioural disengagement coping strategy $M=2.08(S D=1.44)$ were relatively less frequent.

A repeated measures analysis of variance on the coping style scores revealed a significant effect: $F(2,62)=24.73, p<.001$. Bonferroni's post hoc test

Table 1

Mean scores of preference of coping strategies

\begin{tabular}{ll}
\hline Coping strategies & $M(S D)$ \\
\hline 1. Active coping & $4.28(1.45)$ \\
2. Planning & $2.97(1.94)$ \\
3. Instrumental social support & $3.50(1.81)$ \\
4. Emotional social support & $3.60(1.70)$ \\
5. Positive reinterpretation & $3.01(1.67)$ \\
6. Acceptance & $2.05(1.36)$ \\
7. Turning to religion & $3.64(1.64)$ \\
8. Focus on and venting emotions & $2.52(1.65)$ \\
9. Behavioural disengagement & $2.08(1.44)$ \\
10. Substance use & $1.89(1.37)$ \\
11. Restraint coping & $2.80(1.62)$ \\
12. Denial & $2.08(1.53)$ \\
13. Mental disengagement & $2.67(1.51)$ \\
14. Humour & $2.19(1.71)$ \\
15. Suppression of competing activities & $3.11(1.80)$ \\
\hline
\end{tabular}


showed that the problem-focused coping style: $M=$ $3.13(S D=0.99)$ was used more frequently than the emotion-focused coping style $M=2.5(S D=0.73)$ or maladaptive coping style $M=2.28(S D=0.88)$. Maladaptive coping was used less than the emotion-focused coping style. Men used th problem-focused style: $M=3.60(S D=1.10)$ significantly more often than women: $M=3.03(S D=0.84), t(62)=2.50$, $p<.001$. In addition, men also used maladaptive coping more often: $M=2.55(S D=0.70), t(62)=3.34, p<.001$.

The mean scores on preferred coping strategies in the presence of family members and friends are presented in Table 2. Patients sought help mainly from family members: $M=3.06(S D=1.86)$. They were also able to let more negative feelings out in their presence: $M=2.64(S D=1.74)$, in comparison with the coping style in general: $M=2.52(S D=1.65)$. However, the difference was not significant: $Z=0.30, p>$ .05 . The active coping strategy was predominant also in the presence of family members: $M=3.50(S D=$ 1.77), as well as making fun of the health condition using humour: $M=3.48(S D=1.50)$. Coping with the disease by making fun of it was also significant in the presence of friends: $M=3.06(S D=1.71)$. The study identified significantly increased humour as a coping strategy in the presence of family members: $Z=4.61$, $p<.001$, as well as in the presence of friends: $Z=$ $3.39, p<.001$, in comparison to hearing loss humour as a coping method in general: $M=2.19,(S D=1.71)$. The predominant strategy in the presence of friends was total concealment of the medical condition, confirmed also by the significant preference of the strategy denial, which is characterised as pretending nothing had happened: $M=3.25(S D=2.00), Z=5.19$, $p<.001$.

A repeated measures analysis of variance on the coping style scores in the presence of family members and friends revealed a significant effect: $F(5,59)$ $=86.81, p<.001$. Bonferroni's post hoc test showed that there was a significant inhibition of the maladaptive coping style in the presence of friends: $M$ $=1.22(S D=0.59)$ in comparison to the preference of this coping style in the presence of family members: $M=1.99(S D=0.88)$. The men used the emotion-focused coping style more significantly in the presence of family members: $M=2.55(S D=0.45)$ than women: $M=2.30(S D=0.44), t(62)=2.21, p<.05$. However, women used the maladaptive coping more significantly in the presence of friends: $M=1.00(S D=0.01)$, $t(62)=3.74, p<.001$.

\section{DISCUSSION}

Sudden hearing loss represents an acute otolaryngological problem, and due to its sudden onset, unpredictability, and limiting impact on the patient, it is also a very stressful condition. Persons with unilateral deafness experience a significant disability that affects their speech perception, communication, and
Sudden hearing loss and coping strategies

Table 2

Mean scores on preference coping strategies in the presence of family members and friends

\begin{tabular}{lll}
\hline Coping strategies & Family members & Friends \\
\hline 1. Active coping & $M(S D)$ & $M(S D)$ \\
2. Planning & $3.50(1.77)$ & $2.03(1.99)$ \\
3. Instrumental social support & $1.63(1.25)$ & $1.94(1.70)$ \\
4. Emotional social support & $3.06(1.86)$ & $2.00(1.76)$ \\
5. Positive reinterpretation & $3.19(1.83)$ & $1.72(1.26)$ \\
6. Acceptance & $2.55(1.43)$ & $1.69(0.83)$ \\
7. Turning to religion & $1.58(0.66)$ & $2.17(1.57)$ \\
8. Focus on and venting emotions & $2.94(1.90)$ & $1.28(0.67)$ \\
9. Behavioural disengagement & $2.64(1.73)$ & $1.03(0.17)$ \\
10. Substance use & $2.20(1.63)$ & $1.28(0.98)$ \\
11. Restraint coping & $1.33(0.85)$ & $2.42(1.52)$ \\
12. Denial & $2.70(1.50)$ & $3.25(2.00)$ \\
13. Mental disengagement & $1.61(1.10)$ & $1.36(1.02)$ \\
14. Humour & $1.80(1.37)$ & $3.06(1.71)$ \\
15. Suppression of competing activities & $3.48(1.50)$ & $2.75(2.01)$ \\
\hline
\end{tabular}


social interaction (Wie, Pripp, \& Tvete, 2010). Despite this, there has been limited psychological research that has addressed the issue, and studies focused on coping with this condition have been rare. Doctors themselves often underestimate the impact that this condition may have on a patient's life, especially in the case of unilateral hearing loss, claiming that patients still have one fully functional ear. Therefore, it was deemed important for the current research to focus on the use of coping styles during the period of the few days after the first hearing problems occur.

In this study, it was found that respondents preferred the problem-focused coping style. Active coping, turning to religion, and seeking social support were the most frequently used coping strategies in general. These results match the findings of other authors (Hallberg, 1999). Gulášová (2009) explains that coping with any kind of disease is a process, which inevitably begins by collecting information about the disease's course and treatment options, followed by planning the next coping steps. The maladaptive coping style was generally used less frequently. The study also found, similarly to the findings of Hallberg and Carlson (1991), a preference of the coping style that avoids the wider social environment. Gomez and Madey (2001) explain that poor adjustment to hearing loss and poor perceived social support are associated with greater use of maladaptive coping strategies.

The participants sought advice mainly from family members, inhibiting contact with friends. In the presence of friends, concealing their health condition and pretending that nothing had happened were the most dominant coping strategies. Arlinger (2003) also confirms that a frequent reaction to hearing loss is to conceal it from friends due to feelings of shame and frustration due to the inability to hear properly. Murray, Spry, and Mouze (2009) add that this is how the impaired persons tries to cover up the communication barrier.

A further way of dealing with the hearing impairment was using humour in the presence of family members and friends. In additional interviews, the participants said that making fun of their health condition helped them to ease the situation and the worries of their family members. On the other hand, they orally admitted that their hearing loss had led to an increase in experiencing negative emotions. In connection with this, Andersson and Hägnebo (2003) stated that an increase in negative emotions could be related to the feelings of misunderstanding, risk of ridicule or fear that the hearing ability will deteriorate further and result in a total loss of hearing.

The limitations of this study are linked to the fact that the sample was relatively small and had a broad age distribution. In the sample description some important demographic information is also missing, such as religion, alcohol use, or education. In the fu- ture, it would be interesting and beneficial to monitor the coping variables of patients with sudden hearing loss over time (a week, a month, half a year, a year from the first hearing problems) by using a longitudinal design while taking into account the type of treatment. Nevertheless, the study results carry important implications for the development of effective treatment services and for the prevention of mental health problems among people with sudden hearing loss.

\section{CONCLUSIONS}

In conclusion, the results suggest that the start of hearing impairment acts as a trigger for coping strategies aimed at dealing actively with the stressor or strategies related to emotions. Social support of the family represents an important source of information and help for the patients. Humour as a coping strategy is used to ease the present unfavourable situation and conceal the real emotions of the patients from others. Finally, avoidance coping was found to be used especially towards friends.

\section{RefERENCES}

Andersson, G., \& Hägnebo, Ch. (2003). Hearing impairment, coping strategies, and anxiety sensitivity. Journal of Clinical Psychology in Medical Settings, 10, 35-39.

Arlinger, S. (2003). Negative consequences of uncorrected hearing loss - a review. International fournal of Audiology, 42, 17-20.

Carver, C. S., Scheier, M. F., \& Weintraub, J. F. (1989). Assessing coping strategies: A theoretically based approach. Journal of Personality and Social Psychology, 56, 267-283.

Chen, A., \& Most, T. (2009). Auditory, Visual, and Auditory-Visual Perception of Emotions by Individuals With Cochlear Implants, Hearing Aids, and Normal Hearing. Journal of Deaf Studies and Deaf Education, 14, 449-464.

Dimond, M. (2007). Social support and adaptation to chronic illness: The case of maintenance hemodialysis. Research in Nursing and Health, 2, 101-108.

Feher-Prout, T. (1996). Stress and coping in families with deaf children. Journal of Deaf Studies and Deaf Education, 1, 155-166.

Garnefski, N., \& Kraaij, V. (2012). Effects of a cognitive behavioral self-help program on emotional problems for people with acquired hearing loss: a randomized controlled trial. Journal of Deaf Studies and Deaf Education, 17, 75-84.

Gomez, R. G., \& Madey, S. F. (2001). Coping-WithHearing-Loss Model for Older Adults. Journal of Gerontology, 56, 223-225. 
Gulášová, I. (2009). Telesné, psychické, sociálne a duchovné aspekty onkologických ochorení. Martin: Osveta.

Hallam, R., Ashton, P., Sherbourne, L. \& Gailey, L. (2006). Acquired profound hearing loss: Mental health and other characteristics of a large sample, International Journal of Audiology, 45, 715-723.

Hallberg, L. R. (1999). Hearing impairment, coping and consequences on family life. Journal of the Academy of Rehabilitative Audiology, 32, 45-59.

Hallberg, L. R., \& Carlsson, S. G. (1991). A qualitative study of strategies for managing a hearing impairment. British Journal of Audiology, 25, 201-211.

Hasson, D., Theorell, T., Westerlund, H., \& Canion, B. (2010). Prevalence and characteristics of hearing problems in a working and non-working Swedish population. Journal of Epidemiology and Community Health, 64, 453-460.

Lovretić V., Pongrac, K., Vuletić, G., \& Benjak, T. (2016). Role of social support in quality of life of people with hearing impairment. Journal of $A p$ plied Health Sciences, 2, 5-14.

Luey, H. S., Glass, S., \& Elliot, H. (1995). Hard of hearing or deaf: Issues of ears, language, culture, and identity. Social Work, 40, 177-182.

Murray, N. T., Spry, J. L., \& Mauze, E. (2009). Professionals with Hearing Loss: Maintaining That Competitive Edge. Ear and Hearing, 40, 475-484.

Oh, J. K., Park, K., Lee, S. J., Shin, Y. R., \& Choung, Y. H. (2007). Bilateral versus unilateral sudden sensorineural hearing loss. Otolaryngology- Head and Neck Surgery, 136, 87-91.

Rolland J. S. (1987). Chronic Illness and the Life Cycle: A Conceptual Framework. Family Process, 26, 203-221.

Wie, B. O., Pripp, A. H., \& Tvete, O. (2010). Unilateral Deafness in Adults: Effects on Communication and Social Interaction. Annals of Otology, Rhinology \& Laryngology, 119, 772-781.

Wilson, W. R., Byl, F. M, \& Laird, N. (1980). The efficacy of steroids in the treatment of idiopathic sudden hearing loss. A double-blind clinical study. Archives of Otolaryngology, 106, 772-776. 